\title{
The Use of Gulf Cooperation Council Currencies in Carry Trade: A Case Study of United Arab Emirates Dirham
}

\author{
Musaed AlAli ${ }^{1}$ \\ ${ }^{1}$ College of Business Studies, Department of Insurance and Banking, The Public Authority for Applied Education \\ and Training (PAAET), Kuwait \\ Correspondence: Musaed S. AlAli, Department of Insurance and Banking, The Public Authority for Applied \\ Education and Training (PAAET), P.O.Box 2521 Safat, Postal Code 13026, Kuwait. Tel: 965-9981-1250.
}

Received: June 10, 2016

Accepted: June 30, 2016

Online Published: July 4, 2016

doi:10.5430/ijfr.v7n4p117

URL: http://dx.doi.org/10.5430/ijfr.v7n4p117

\begin{abstract}
This paper examines the profitability of using the United Arab Emirates dirham as a U.S. dollar pegged currency in carry trade. Carry trade is a speculative currency strategy that takes advantage of interest rate differential between two currencies. Literature has shown that such strategy generates returns that are almost similar to that of the S\&P 500 but with double its Sharpe ratio. Results of this study show that implementing such strategy using pegged currencies produced positive returns and these results were improved when the selection process was enhanced with forecasting element.
\end{abstract}

Keywords: carry trade, Gulf Cooperation Council, random walk, uncovered interest rate parity (UIP)

\section{Introduction}

Carry trade is a simple strategy that is conducted by all levels of investors from sophisticated sovereign wealth funds to simple housewives. Carry trade can be conducted in many ways, but its simplest form is investing in high-interest currencies using low-interest currencies for funding. It has been well documented that such strategy is profitable generating a return that is similar to that of the S\&P 500 as concluded by Burnside et al. (2006), Lustig and Verdelhan (2007), Lusting et al. (2011), Menkhoff et al. (2012), Rafferty (2012), Bhatti (2012) and many others. Burnside et al. (2006) found that for the period from 1977 to 2005 the cumulative return realised from carry trade was similar to that of investing in the S\&P 500. Not only carry trade produces returns that are similar to the S\&P 500 but it produces a Sharpe ratio that is double of that of the stock markets. Neely and Weller (2013) showed that there is a growing body of literature indicating that carry trade has statistically and economically significant positive excess returns and a Sharpe ratio about double that of equity markets. Burnside et al. (2007) for the period spanning 1997-2006 using the U.S. dollar as the funding currency in carry trade. They reported that carry trade is a profitable strategy producing an annualized Sharpe ratio of 1.32 compared to 0.23 for the U.S. stock market.

Profitability of carry trade is a result of the failure of the uncovered interest rare parity (UIP). Where UIP is an arbitrage condition indicating that there should be no profit opportunity from interest rate differential between two currencies since currency movement should offset the difference. But, literature has shown that that UIP does not hold as concluded by Engle (1996), Floor and Rose (2002), Szilagyi and Batten (2006). Not only that UIP does not stand, but it has been noticed by Brunnermeier et al. (2008), Clarida et al. (2009) and others that currencies with high-interest rates tend to appreciate against low-interest rate currencies contradicting UIP. This led to an impression among some researchers like Gyntelberg and Remolona (2007) and Baillie and Chang (2011) that there is a relation between profitability and the failure of UIP. This relation is questioned by Olmo and Pilbeam (2009) where they showed that the implied empirical failure of the UIP condition does not necessarily generate excess return. Moosa and Halteh (2012) argued that despite the failure of UIP being a necessary condition for generating profits in carry trade, it is not sufficient enough. They justify their argument by pointing out that if the low-interest rate currency appreciates against the high-interest rate currency by more than the interest rate differential itself, this would satisfy the failure of UIP condition but at the same time produces a losing carry trade position.

Carry trade is a short-term investment strategy producing to some extend continues small returns. So, in order to increase these small returns, leverage should be a crucial feature of carry trade as stated by Liu et al. (2012). Carry traders are encouraged to leverage their positions since literature show that highly leveraged carry trade could 
produce an annualized return of almost $46 \%$ compared to $5 \%$ for less leverages carry trade (Darvas, 2009). But according to Hattori and Shin (2009), leveraging is a double-sided sward since it magnifies losses as well as gains. That is why the Economist (2007) described carry trade as "picking up nickels in front of steamrollers: you have a long run of small gains but eventually get squashed". Carry trade is conducted during periods when interest rate differential is high and exchange rate volatility is low. Based on Galati et al. (2007), Brunnermeier et al. (2008) and Jylha and Suominen (2011) such condition of high interest rate differential and low exchange rate volatility is unsustainable, since they have shown that there is a positive correlation between interest rate differential and number of speculators which translates to higher volatility. During the period of high interest rate differential and low volatility capital starts arriving slowly causing investment currency to appreciate against the funding currency which is in line with Brunnermeier et al. (2008) and Clarida et al. (2009) findings. But, that calmness in exchange rate markets is deceiving since according to Plantin and Shin (2006) and Olmo and Pilbeam (2009) exchange rate markets like any other financial market tend to exhibit the classical price pattern of "going up the stairs, and coming down in the elevator". Such huge losses are due to an unexpected exchange rate swings that trigger stop loss orders fuelling it more.

Carry trade is a leveraged strategy; this feature could have catastrophical consequences during high exchange rate volatility periods. Due to the nature of carry trade any exchange rate swings would have a snowball effect on the market since it will trigger stop-loss orders for both carry traders and foreign exchange speculators. Such scenario happened many times in the past, for example, between 5-9 October 1998 the Japanese yen appreciated against the U.S. dollar from 134.54 to 117 that is almost 13\%. Also between July and October 2008 the Japanese yen appreciated against the Australian dollar by almost $45 \%$ from 104.18 to 56.97 as seen in Figure 1.

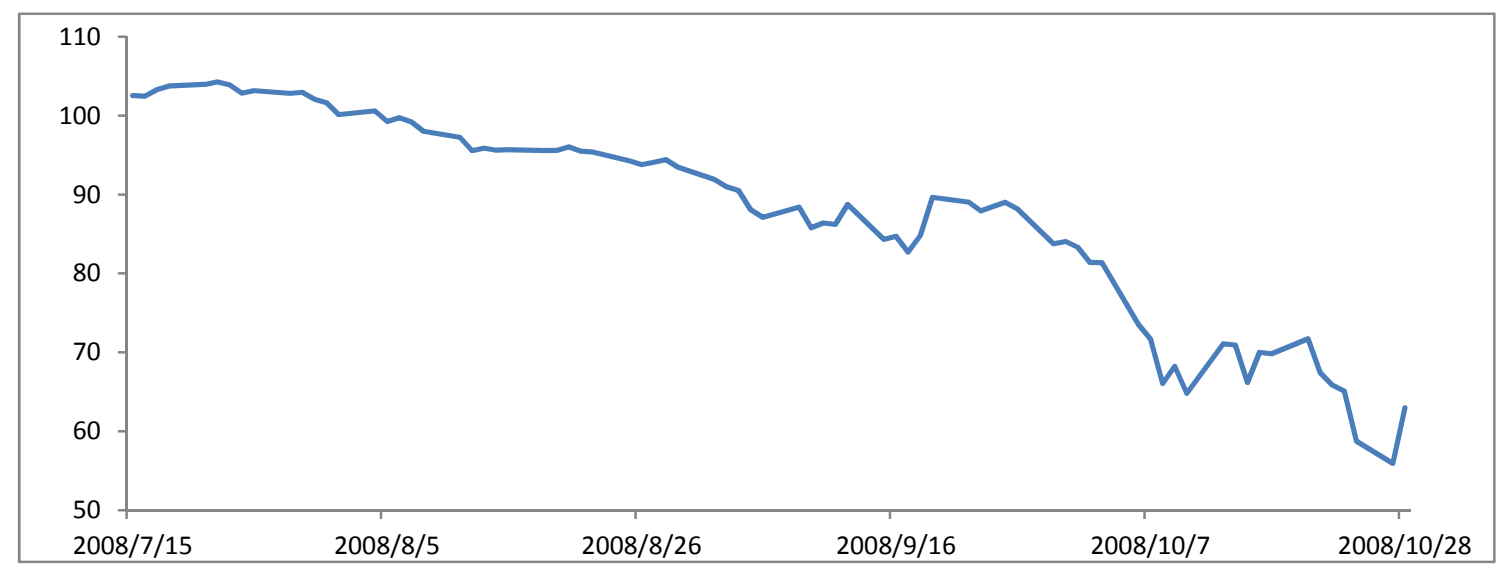

Figure 1. The JPY/AUD Exchange Rate (July 2008 - October 2008)

Predicting such currency crashes is not an easy task but it is crucial for carry traders to avoid losses. It has been concluded by many such as Jorda and Taylor (2009), Moosa (2010), Schmidbauer et al. (2010), Li (2011), Moosa and Halteh (2012) and others that adding a forecasting element into the decision-making process could reduce exchange rate risk, enhance profitability and improve risk-adjusted returns. For example, Della Corte et al. (2009) concluded that there is a significant economic benefit from exploiting the deviations from UIP by forecasting currency returns. In addition, $\mathrm{Li}$ (2011) founded that profitability of carry trade and risk-return measures can be enhanced by using forecasts. Further, Bhatti (2012) found that the expected change in the exchange rate of the funding against the target currency over the holding period does effects the return on carry trades and that interest differential is not the only factor determining the return in carry trades. Della Corte et al. (2009) found that strategies based on forecasts yield large economic gains over the random walk benchmark.

Meese and Rogoff (1983) used the magnitude of error to evaluate the goodness of the forecasting models. The failure to outperform these measures led to a believe among researchers and practitioners that a naïve forecasting model would work just as well as professional forecasts if not better. Abhyankar et al. described Meese-Rogoff findings as a "major puzzle in international finance". Frankel and Rose (1995) argued that the random walk puzzle caused a pessimistic effect on the field of exchange rate modelling. Engel et al. (2007) describe the current position of 
forecasting models by stating the "explanatory power of these models is essentially zero". Fair (2008) describes exchange rate equations as "not the pride of open economy macroeconomics" and argues that the "general view still seems pessimistic". However, researchers such as Leitch and Tanner (1991), Chow et al. (2007) and Moosa (2013) questioned the rationale behind buying forecasting models by profit-maximising firms since measures of forecasting accuracy indicate that the random walk produces better forecasts for free. Chow et al. (2007) based on their findings, suggested that it might not be appropriate to use forecast error measures to judge the quality of professional forecasts and profit should be included as a judging criterion. Cheung et al. (2005) stated that the use of criteria other than the mean square error (MSE) is not "changing the rules of the game" and minimizing the mean square error may not be important from an economic standpoint, implying that relying on mean square error may result in overlooking other important aspects of prediction, such as profitability, particularly at the long horizon.

When it comes to forecasting, one size does not fit all. That is why when asked whether or not fundamentals can predict exchange rate movements, the answer "depends on how the question is asked" and this should relate to the purpose of the forecast (Thoma, 2008). When looking at the forecasting model results from an economical point-of-view it can be seen that there is no obvious relationship between magnitude of error measures and profitability as concluded by Boothe and Glassman (1987). Adding to it, Leitch and Tanner (1991) found a strong relation between direction accuracy and profitability, but not between error measures and profitability. Moosa and Burns (2012) found that profitability is invariably related to direction accuracy, while random walk is bad in predicting the direction. Engle and Hamilton (1990) supported the use of direction accuracy, by describing it as "not a bad proxy for a utility-based measure of forecasting performance". It has been documented by Eun and Sabherwal (2002) that the majority of the banks they examine show some evidence of outperforming the random walk on the profitability side. Moosa (2013) suggests that profitability is the ultimate test of forecasting accuracy.

\section{Methodology}

This paper examines two strategies, the first one is based on interest rate differential and nothing else when taking the decision the conduct carry trade. While the second strategy takes into account both interest rate differential and the expected percentage change in the exchange rate.

Let $i_{x}$ and $i_{y}$ be the interest rates for currencies $x$ and $y$, respectively. In addition, let $S$ be the spot rate between the two currencies measured as one unit of $y$ against $x$, so appreciation of $y$ against $x$ would result in a higher $S$, and vice versa. Under conventional carry trade, carry traders would go long currency $y$ and short currency $x$ if $i_{y}>i_{x}$ and vice versa. In this case the return on carry trade is given by;

$$
\pi=\frac{s_{t+1}}{s_{t}}\left(1+i_{y}\right)-\left(1+i_{x}\right)
$$

which can be rewritten as

$$
\pi=\left(i_{y}-i_{x}\right)+\dot{S}_{t+1}
$$

Where $\dot{S}_{t+1}$ is the percentage change in the exchange rate between $t$ and $t+1$. The carry trade operation is implicitly based on the assumption of random walk without drift (Moosa, 2004), which means that $\dot{S}_{t+1}=0$. Thus, carry trade is profitable as long as $\left(i_{y}-i_{x}\right)>-\dot{S}_{t+1}$. (That is, as long as the interest rate differential is larger than the depreciation of currency $y$ against currency $x$.)

Because of the changes in interest rates differential, it is necessary to switch the role of the currencies, so the general formula for calculating the rate of return on the carry trade will be as follow:

$$
\pi=\left\{\begin{array}{lll}
\left(i_{y}-i_{x}\right)+\dot{S}_{t+1} & \text { if } & i_{y}>i_{x} \\
\left(i_{x}-i_{y}\right)-\dot{S}_{t+1} & i_{y}<i_{x}
\end{array}\right.
$$

The forecasting-based strategy involves calculating the expected rate of return and conducting the position accordingly. The expected return is calculated as follows:

$$
\pi^{e}=\left(i_{y}-i_{x}\right)+\dot{S}_{t+1}^{e},
$$

where $\dot{S}_{t+1}^{e}$ is the calculated percentage change in exchange rate based on the forecasting model. Thus, we go long $y$ and short $x$ if $\pi^{e}>0$ and vice versa. In that case, the profitability of the forecasting-based strategy is as follows:

$$
\pi=\left\{\begin{array}{lll}
\left(i_{y}-i_{x}\right)+\dot{S}_{t+1} & & \pi^{e}>0 \\
\left(i_{x}-i_{y}\right)-\dot{S}_{t+1} & \pi^{e}<0
\end{array}\right.
$$


Since the Emirates dirham is pegged to the U.S. dollar at 3.67 Dirhams per dollar, with a very narrow fluctuation band, the exchange rate of the dirham will reflect the economic conditions of the U.S. dollar. Thus, when calculating for $\dot{S}_{t+1}^{e}$ using the flexible price monetary model of exchange rates, we will be doing so for the U.S. dollar.

$$
s_{t}=\alpha_{0}+\alpha_{1}\left(m_{a, t}-m_{b, t}\right)+\alpha_{2}\left(y_{a, t}-y_{b, t}\right)+\alpha_{3}\left(i_{a, t}-i_{b, t}\right)+\varepsilon_{t},
$$

where $s$ is the natural $\log$ of the exchange rate, $m$ is the natural $\log$ of the money supply, $y$ is the natural $\log$ of the industrial production, $i$ is the nominal interest rate, $\varepsilon$ is the error factor, and $a$ and $b$ refer to the countries whose currencies are involved. Here, country $b$ will have its currency as the base currency in the exchange rate pair. The forecasted exchange rate will be as follows:

$$
\hat{s}_{t+1}=\hat{\alpha}_{0}+\hat{\alpha}_{1}\left(m_{a, t+1}-m_{b, t+1}\right)+\hat{\alpha}_{2}\left(y_{a, t+1}-y_{b, t+1}\right)+\hat{\alpha}_{3}\left(i_{a, t+1}-i_{b, t+1}\right),
$$

Where $\hat{\alpha}_{0}$ is the estimated value of $\alpha_{0}$ and so on. To convert the natural log forecasted exchange rate to estimated exchange rate, the following is applied:

$$
S_{t+1}^{e}=\exp \left(\hat{s}_{t+1}\right)
$$

$\dot{S}_{t+1}^{e}$ is calculated from $S_{t+1}^{e}$ and $S_{t}$, which can be used to calculate the expected return in equation (4).

\section{Data and Empirical Results}

The empirical results presented in this paper are based on six currency combinations involving the Emirates dirham (AED) against the Japanese yen (JPY), the British pound (GBP), the Korean won (KRW), the Singaporean dollar (SGD), the Canadian dollar (CAD), and the Swiss franc (CHF). Monthly data were used for the period of January 2001 to December 2011. Data were obtained from the International Financial Statistics (CD-ROM) and DataStream terminal.

Using the magnitude of error measures to examine the goodness of the forecasting model against the random walk as conducted by Meese and Rogoff (1983). It can be seen from table (1) that the random walk outperformed the monetary model in all pairs. Looking at the average of the six pairs in each strategy, as shown in table (2), shows that the average mean absolute error (MAE) for the random walk was 1.83 compared to 7.28 for the forecasting-based strategy. The same results continue when it comes to the mean squared error (MSE) where the forecasting-based strategy produced 92.73 compared to the 7.12 for carry trade. In terms of the root mean squared error (RMSE) the results were 2.56 and 9.44 for both conventional carry trade and forecasting based strategy respectively. Moosa and Burns (2013) tested for the statistical significance of the difference in the RMSE of the random walk and exchange rate model and found that the random walk cannot be outperformed - that is, the RMSE of the random walk is numerically smaller and statistically different to that of various monetary models. According to Greenaway-McGrevy et al. (2012) in order for the forecasting model to beat the random walk in terms of the magnitude of error, then the The Theil inequality coefficient (U) should be less than one. By looking at table (1) it can be seen that none of the six pairs was able to produce a number less than one. This means that the

\begin{tabular}{|c|c|c|c|c|c|c|c|c|c|c|c|c|}
\hline & \multicolumn{2}{|c|}{ SGD/AED } & \multicolumn{2}{|c|}{ AED/GBP } & \multicolumn{2}{|c|}{ JPY/AED } & \multicolumn{2}{|c|}{ AED/KRW } & \multicolumn{2}{|c|}{ CAD/AED } & \multicolumn{2}{|c|}{ CHF/AED } \\
\hline & $\mathrm{CT}$ & $\mathrm{FC}$ & $\mathrm{CT}$ & $\mathrm{FC}$ & $\mathrm{CT}$ & $\mathrm{FC}$ & $\mathrm{CT}$ & $\mathrm{FC}$ & $\mathrm{CT}$ & $\mathrm{FC}$ & $\mathrm{CT}$ & $\mathrm{FC}$ \\
\hline MAE & 1.11 & 4.50 & 1.84 & 6.33 & 1.98 & 7.75 & 2.11 & 8.39 & 1.41 & 6.88 & 2.51 & 9.84 \\
\hline MSE & 2.21 & 40.15 & 6.03 & 70.31 & 6.45 & 86.35 & 14.10 & 111.93 & 3.64 & 90.67 & 10.27 & 156.94 \\
\hline RMSE & 1.49 & 6.34 & 2.46 & 8.39 & 2.54 & 9.29 & 3.76 & 10.58 & 1.91 & 9.52 & 3.20 & 12.53 \\
\hline $\mathbf{U}$ & \multicolumn{2}{|c|}{4.26} & \multicolumn{2}{|c|}{3.41} & \multicolumn{2}{|c|}{3.66} & \multicolumn{2}{|c|}{2.81} & \multicolumn{2}{|c|}{4.98} & \multicolumn{2}{|c|}{3.92} \\
\hline Ave Interest Diff & \multicolumn{2}{|c|}{2.63} & \multicolumn{2}{|c|}{0.30} & \multicolumn{2}{|c|}{3.47} & \multicolumn{2}{|c|}{2.18} & \multicolumn{2}{|c|}{2.28} & \multicolumn{2}{|c|}{2.84} \\
\hline Direction Accuracy \% & & 55.87 & & 53.07 & & 49.72 & & 60.89 & & 48.04 & & 47.49 \\
\hline Confusion Rate \% & & 44.13 & & 46.93 & & 50.28 & & 39.11 & & 51.96 & & 52.51 \\
\hline Mean Return & 2.22 & 2.21 & 2.05 & 0.72 & 1.11 & 3.92 & -0.64 & 10.83 & 0.64 & 1.52 & -0.10 & 1.46 \\
\hline Cumulative Return & 36.47 & 36.26 & 28.60 & 5.36 & 11.31 & 69.42 & -11.38 & 347.91 & 6.48 & 21.42 & -10.17 & 13.49 \\
\hline Standard Deviation & 18.22 & 17.96 & 29.57 & 29.63 & 30.68 & 30.45 & 46.21 & 43.89 & 23.02 & 22.97 & 38.68 & 38.65 \\
\hline Sharpe Ratio & 0.122 & 0.123 & 0.069 & 0.024 & 0.036 & 0.129 & -0.014 & 0.247 & 0.028 & 0.066 & -0.003 & 0.038 \\
\hline VaR 99\% & 3.53 & 3.92 & 7.79 & 6.08 & 5.95 & 4.74 & 11.59 & 5.30 & 4.91 & 4.16 & 6.36 & 6.37 \\
\hline VaR 95\% & 1.76 & 2.09 & 3.62 & 3.85 & 4.26 & 3.57 & 4.32 & 3.11 & 2.82 & 2.56 & 5.04 & 4.73 \\
\hline
\end{tabular}
forecasting-based strategy was unable to beat the random walk in terms or error measures.

Table 1. Results for individual pairs

CT is carry trade and FC is the forecasting based strategy. 
Many researchers such as Boothe and Glassman (1987), Leitch and Tanner (1991), Mark and Choi (1997), Cheung et al. (2005) and Moosa and Burns (2012) conceder the economic aspects of the forecasting model when evaluating its quality. Moosa (2013) suggests that profitability is the ultimate test for forecasting accuracy. When examining the overall returns for the two strategies it can be seen that the forecasting-based strategy produced much better return than the conventional carry trade. For the average of the six pairs carry trade produced $0.88 \%$ compared to $3.44 \%$ for the forecasting-based strategy. On an individual level SGD/AED produced the highest return of $2.22 \%$ for carry trade compared to $10.83 \%$ for $\mathrm{AED} / \mathrm{KRW}$ on the forecasting-based strategy. The most improvement came in $\mathrm{AED} / \mathrm{KRW}$ where the return improved from $-0.64 \%$ under carry trade to $10.83 \%$ under the forecasting-based strategy. The reason for such improvement was the ability of the monetary model to capture most of the exchange rate movement especially during the Asian financial crisis in the 1997.

Table 2. Cumulative results

\begin{tabular}{ccc}
\hline & CT & FC \\
\hline MAE & 1.83 & 7.28 \\
MSE & 7.12 & 92.73 \\
RMSE & 2.56 & 9.44 \\
U & \multicolumn{2}{c}{3.84} \\
Ave Interest Diff & \multicolumn{2}{c}{2.28} \\
Direction & \multicolumn{2}{c}{$52.51 \%$} \\
Accuracy \% & \multicolumn{2}{c}{} \\
Confusion Rate \% & \multicolumn{2}{c}{$47.49 \%$} \\
Mean Return & 0.88 & 3.44 \\
Cumulative Return & 10.22 & 82.31 \\
Standard Deviation & 31.06 & 30.59 \\
Sharpe Ratio & 0.04 & 0.10 \\
VaR 99\% & 6.69 & 5.10 \\
VaR 95\% & 3.64 & 3.32 \\
\hline
\end{tabular}

$\mathrm{CT}$ is carry trade and FC is the forecasting based strategy.

Although AED/KRW had the highest direction accuracy out of the six pairs under study and had the highest return that does not mean that there is a direct relation between direction accuracy and mean return. The second and the third highest accuracy rate pairs which are SGD/AED and AED/GBP had lower returns under forecasting-based strategy than under conventional carry trade as seen in figure 2. Adding to that CAD/AED and CHF/AED despite having accuracy rate that is lower than $50 \%$, they both showed improvements in their returns. Calculating the correlation coefficient between direction accuracy and mean return for the forecasting-based strategy did not show statistically significant relation between them. These results contradicts the findings of Engle and Hamilton (1990), Leitch and Tanner (1991) and Moosa and Burns (2012) that there is a relation between direction accuracy and returns.

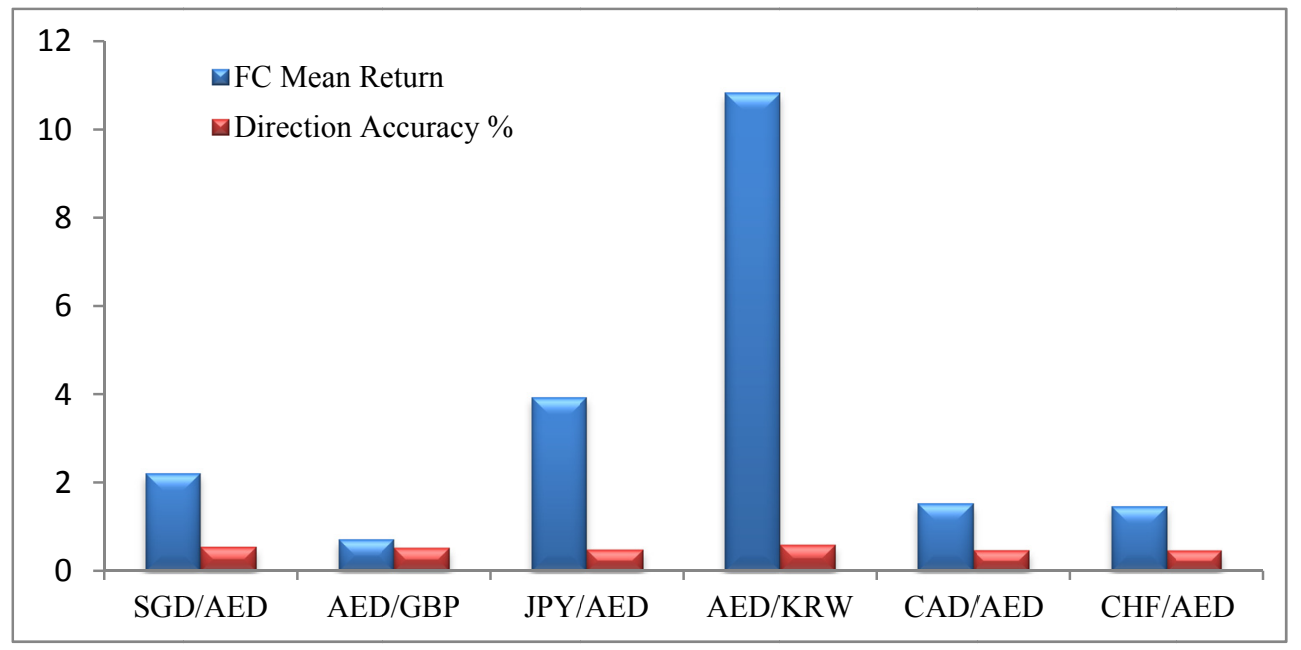

Figure 2. Direction accuracy vs. forecasting-based strategy mean return 
The same conclusion was drawn when examining the relation between direction accuracy and the change in return between conventional carry trade and forecasting-based carry trade as seen in figure 3 . The assumption here is that there is a direct relation between direction accuracy and the improvement in returns. By running the regression between direction accuracy and the difference in return between the two strategies, we could not find any statistical significant relation between them.

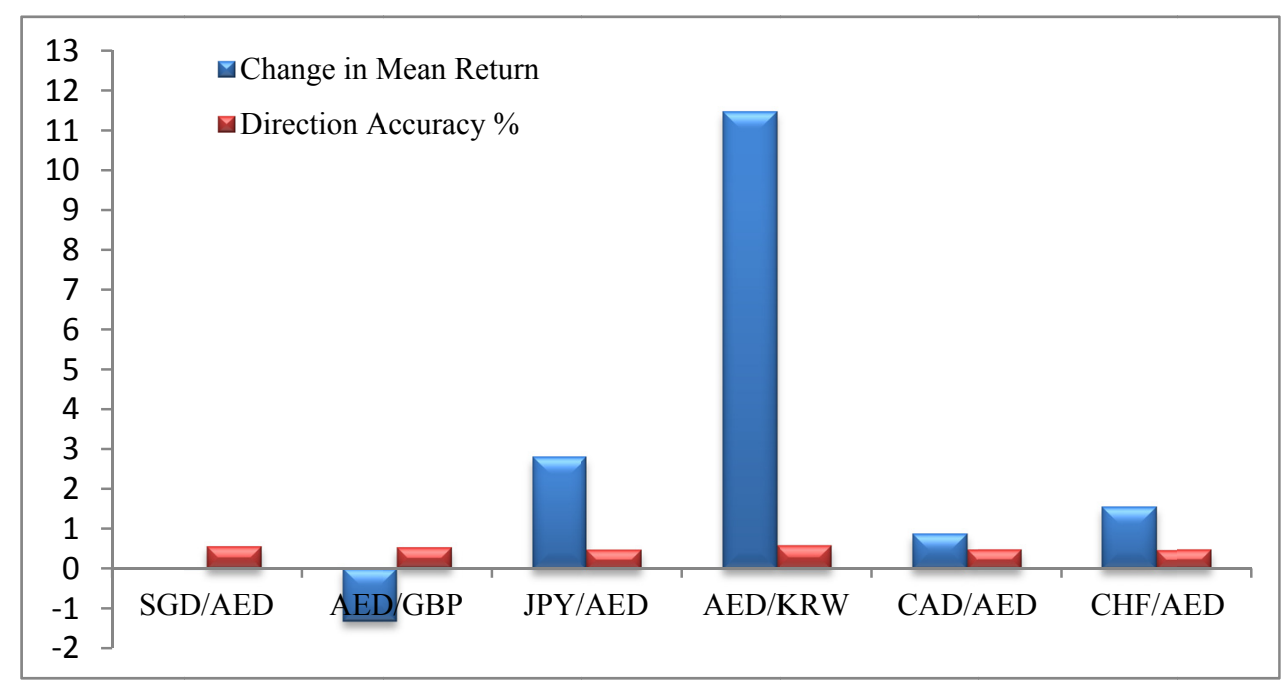

Figure 3. Direction accuracy vs. change in mean return

While carry traders base their decision to enter a carry trade position on interest rate differential, many researchers such as Moosa (2008), Olmo and Pilbeam (2009), Moosa and Halteh (2012) and others argue that there is no clear-cut relation between interest rate differential and carry trade returns. By looking at the results, it can be seen that while JPY/AED had the largest interest rate differential of 3.47\% it did not produce the highest mean return. Adding to it, CHF/AED which had the second highest interest rate differential produced a negative return. On the other hand AED/GBP had the lowest interest rate differential but had the second highest mean return as seen in figure 4. When examining the relation between interest rate differential and mean return we could not find any statistically significant relation there. These conclusions are in line with Moosa (2008), Olmo and Pilbeam (2009), Moosa and Halteh (2012) findings.

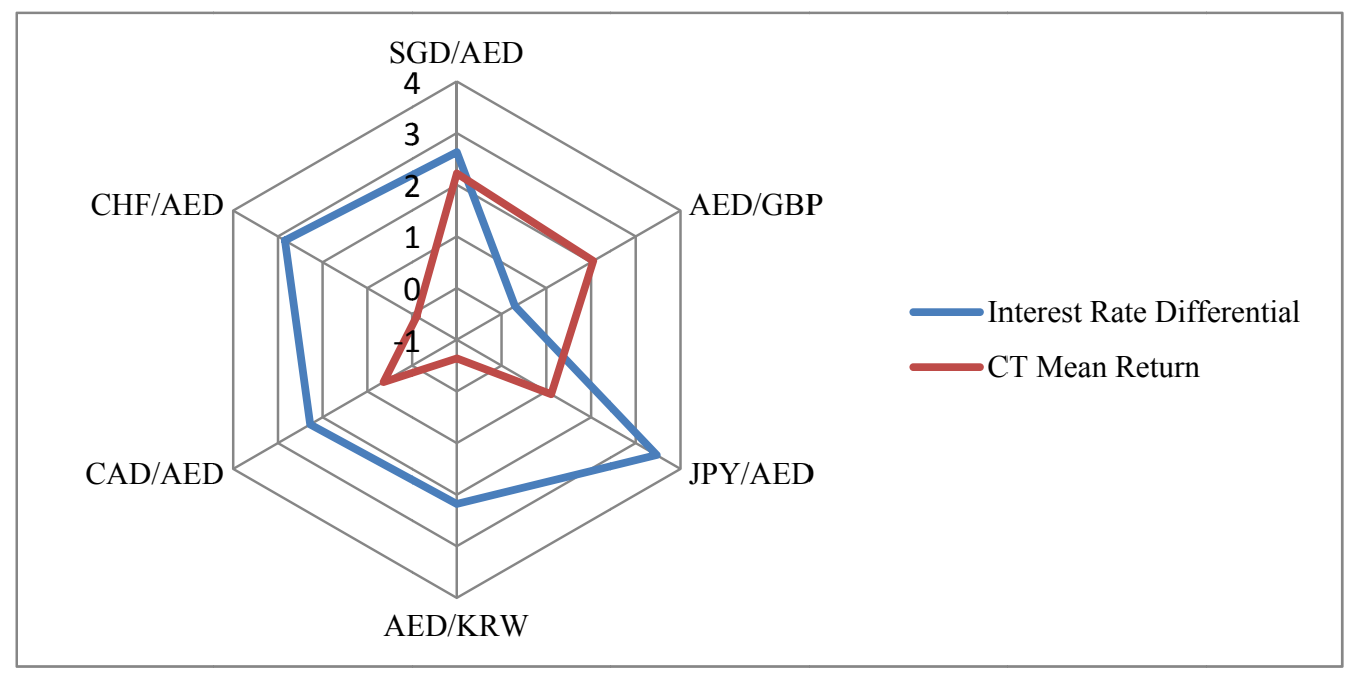

Figure 4. Interest rate differential vs. conventional carry trade mean return 
Comparing the standard deviation between the six pairs under investigation, it can be seen that the standard deviation was improved in all pairs except for AED/GBP where the standard deviation was lower in conventional carry trade. On the strategy level, it can be seen that the standard deviation has improved from 31.06 to 30.59 for conventional carry trade and forecasting-based strategy respectively. Number of researchers such as Galati et al. (2007), Hattori and Shin (2007), Brunnermeier et al. (2008), Tosborvorn (2010) and Jylha and Souminen (2011), documented a strong relation between interest rate differential and exchange rate volatility. The results on an individual currency pair level is illustrated in table 3. Based on the literature interest rate affects the volatility of the exchange rate, for that we used the exchange rate volatility as the dependent variable and the interest rate differential as the independent variable. The regression model can be seen in equation (9).

$$
v o l=a+b \text { ir }
$$

Where $v o l$ is the exchange rate volatility and $i r$ is the interest rate differential. The results show that there is a statistically significant relation between interest rate volatility and interest rate differential in the six pairs. But, we could not determine the direction of the relation if it is direct or inverse since four pairs showed a negative relation and two showing a direct relation. The relation between the interest rate differential for the six pairs against the volatility can also be seen in Figure 5.

Table 3 . The Relation between interest rate differential vs. exchange rate volatility

\begin{tabular}{|c|c|c|c|c|c|c|}
\hline & SGD/AED & AED/GBP & JPY/AED & AED/KRW & CAD/AED & CHF/AED \\
\hline$i r$ & $\begin{array}{c}-0.86^{* * *} \\
(-3.55)\end{array}$ & $\begin{array}{c}-0.973 * * * \\
(-5.96)\end{array}$ & $\begin{array}{c}0.631 * * * \\
(4.67)\end{array}$ & $\begin{array}{c}1.972 * * * \\
(9.06)\end{array}$ & $\begin{array}{c}-0.660^{*} \\
(-2.02)\end{array}$ & $\begin{array}{c}-0.515^{* *} \\
(-3.03)\end{array}$ \\
\hline$a$ & $\begin{array}{c}1.59 * * * \\
(25.79)\end{array}$ & $\begin{array}{r}2.06^{* * *} \\
(94.23)\end{array}$ & $\begin{array}{l}1.90^{* * *} \\
(44.01)\end{array}$ & $\begin{array}{l}1.70^{* * *} \\
(31.70)\end{array}$ & $\begin{array}{l}1.81 * * * \\
(27.31)\end{array}$ & $\begin{array}{c}2.41 * * * \\
(53.76)\end{array}$ \\
\hline $\mathrm{R}$ square & 0.070 & 0.174 & 0.115 & 0.328 & 0.024 & 0.052 \\
\hline $\mathrm{N}$ & 170 & 170 & 170 & 170 & 170 & 170 \\
\hline
\end{tabular}

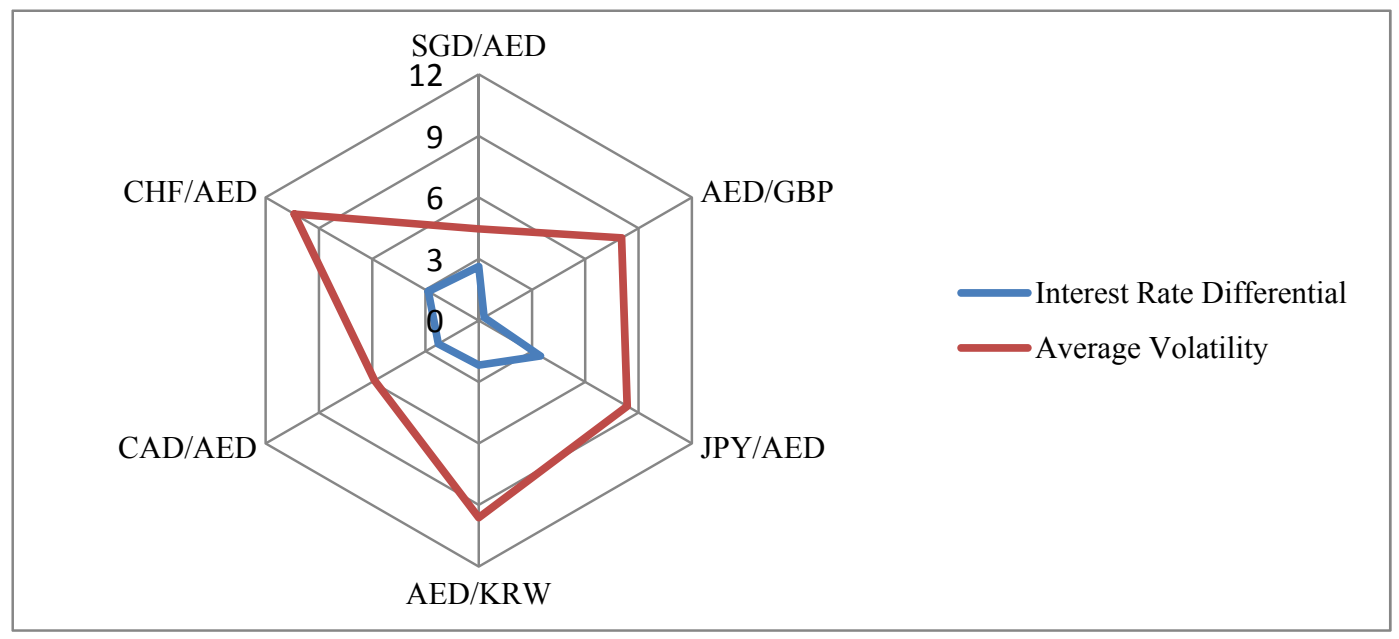

Figure 5. Interest rate differential vs. average volatility

Sharpe ratio is a measure of risk-adjusted return; it is calculated by dividing the mean return over the standard deviation. By looking at the results, it can be seen that the Sharpe ratio has improved as a result of introducing the forecasting element in the selection process in all pairs except for AED/GBP where the conventional carry trade 
produced a better Sharpe ratio. As to comparing the two strategies, it can be seen that the forecasting-based strategy produced a better Sharpe ratio than the conventional carry trade as concluded by Jorda and Taylor (2009), Moosa (2010), Schmidbauer et al. (2010), Li (2011), Moosa and Halteh (2012) and others. Burnside et al. (2007), Bhatti (2012), Neely and Weller (2013), and others argued that carry trade in its simplest forms produced a better Sharpe ratio than the S\&P 500 if not double. Table 4 illustrates the main results between the two strategies of carry trade and the S\&P 500. It can be seen that the S\&P 500 performed better than the conventional carry trade in terms of mean return and the Sharpe ratio. Where conventional carry trade produced a mean return on $0.88 \%$ compared to $1.87 \%$ for the S\&P 500 and Sharpe ratio of 0.028 compared to 0.034 for the equity index. These findings contradicts the conclusions of Burnside et al. (2007), Bhatti (2012), Neely and Weller (2013). But when it comes to the forecasting-based strategy, it can be seen that it outperformed the S\&P 500 in all categories as concluded by Darvas (2009) and others.

Table 4. Comparative results between carry trade and S\&P 500

\begin{tabular}{llll}
\hline & CT & FC & S\&P 500 \\
\hline Mean Return & 0.88 & 7.28 & 1.87 \\
$\begin{array}{l}\text { Standard } \\
\text { Deviation }\end{array}$ & 31.06 & 30.59 & 54.72 \\
Sharpe Ratio & 0.028 & 0.10 & 0.034 \\
VaR 99\% & 6.69 & 5.10 & 10.1 \\
VaR 95\% & 3.64 & 3.32 & 6.99 \\
\hline
\end{tabular}

Looking at the value-at-risk for the six pairs, it can be seen that at the $99 \%$ confidence level, the value-at-risk has improved in four out of the six pairs when the model was enhanced with a forecasting element. The two pairs that had a better VaR at the $99 \%$ confidence level in conventional carry trade than in forecasting-based strategy were SGD/AED and CHF/AED. The best improvement came in AED/KRW when VaR 99\% went from 11.59 to 5.30 as a result of the introduction of the forecasting element. On the $95 \%$ confidence level, four pairs showed improvement under the forecasting-based strategy while SGD/AED and AED/GBP where better under the conventional carry trade. By comparing on a strategy level, it can be concluded that the forecasting-based strategy improved the value-at-risk in both the $99 \%$ and the $95 \%$ confidence level. When comparing the VaR at both $99 \%$ and $95 \%$ confidence level for both strategies against the S\&P 500, it can be seen that both strategies outperformed the S\&P 500 in that category. On an individual level, all currency pairs had a VaR that is lower than that for the S\&P 500 except for AED/KRW on the conventional carry trade where the VaR 95\% for the S\&P 500 was lower.

Due to the highly leveraged nature of carry trade, it is vulnerable to exchange rate volatility. Jorda and Taylor (2009) showed that carry trade performs badly during high volatility periods. Kohler (2008) defines a crisis as times of large market downturns or as periods of exceptionally high volatility. Ranaldo and Soderlind (2010) have compiled a list of economic, political and natural disaster events by a news search, which they use to study the performance of several major currencies on those dates. Economic disasters include financial crises, defaults or bankruptcies. Political disasters include wars, terrorism and bombings. Natural disasters include hurricanes, tornados, tsunamis and earthquakes. They conclude that financial crises have the most effect on currency markets than all other types of crises.

Stock markets do not necessarily crash in times of disasters although return is typically negative. However, high interest currencies always perform poorly in these times as all currencies depreciate against the U.S. dollar in times of disasters. This confirms the "safe haven" properties of the U.S. dollar as a reserve currency as documented by Maggiori (2011). Despite the fact that the global financial crisis started in the U.S., with Lehman Brothers' bankruptcy, the U.S. dollar appreciated during that period. Adrian et al. (2009) argues that the reason for the appreciation of the U.S. dollar during that period was the funding liquidity. This is particularly true for the many financial institutions that were building up their balance sheets with short-term debt. Having the dirham pegged to the U.S. dollar does not mean it would perform well when used in carry trade during financial crises.

The volatility and the return of both carry trade strategy and forecasting-based strategy are examined during the three largest financial crises: the East Asia financial crisis, the global stock market crash, and the global financial crisis. 
The results shown in Table 5 confirm the findings of Menkhoff et al. (2012) that carry trade in its simplest form performs poorly during high volatility periods.

Table 5. Carry trade during financial crises

\begin{tabular}{cccccccccc}
\hline $\begin{array}{c}\text { Crisis } \\
\text { Periods }\end{array}$ & \multicolumn{3}{c}{$6 / 1997-1 / 1998$} & \multicolumn{3}{c}{$2 / 1998-7 / 2008$} & \multicolumn{3}{c}{$8 / 2008-12 / 2011$} \\
& & & & & & & \\
\hline & CT & FC & SD & CT & FC & SD & CT & FC & SD \\
\hline SGD/AED & 2.62 & 2.65 & 22.98 & 0.05 & -0.07 & 2.27 & 0.08 & 0.44 & 18.74 \\
AED/GBP & 0.10 & -0.39 & 21.57 & 0.30 & 0.09 & 25.12 & -0.26 & 0.12 & 41.96 \\
JPY/AED & 1.52 & 1.44 & 29.81 & 0.20 & 0.28 & 30.50 & -0.58 & 0.22 & 28.00 \\
AED/KRW & -6.65 & 3.94 & 130.74 & 0.49 & 0.62 & 27.40 & -0.07 & 1.18 & 46.70 \\
CAD/AED & 0.84 & 0.10 & 9.79 & -0.08 & -0.01 & 19.69 & 0.24 & 0.66 & 32.55 \\
CHF/AED & 0.95 & 0.88 & 32.49 & -0.02 & 0.03 & 37.11 & -0.24 & 0.19 & 46.70 \\
Average & -0.10 & 1.44 & 41.23 & 0.15 & 0.16 & 22.93 & -0.14 & 0.47 & 35.77 \\
\hline
\end{tabular}

The standard deviation for the exchange rate between AED and the six currencies for the whole sample period was 30.75, but it went up during the East Asia financial crisis and global stock market crash that occurred in June 1997 and October 1997, respectively to 41.23 . As a result, the mean return for the period went down to $-0.10 \%$ versus an average of $0.88 \%$ for the entire period. On the other hand, the forecasting-based strategy produced higher than average returns by achieving $1.44 \%$ for the same period. This confirms Eun and Sabherwal (2002) and Corte et al. (2009) who state that forecasting-based strategies yield large economic gains over the random walk benchmark. The global financial crisis from August 2008 to December 2011 confirmed these results. The standard deviation went up to 35.77 resulting in a drop in mean return for that period to $-.14 \%$ for carry trade and $0.47 \%$ for the forecasting-based strategy. This compared to $0.88 \%$ and $3.44 \%$ for carry trade and forecasting based strategy during the entire period, respectively.

\section{Conclusion}

The results presented in this paper shows that using a pegged currency in carry trade can yield positive returns. The use of the United Arab Emirates dirham (AED) in carry trade has shown to be profitable and that the use of the gulf cooperation council currencies in carry trade can be rewarding as concluded by AlAli and AlKulaib (2015) and AlAli et al. (2016). On the other hand, by using AED in conventional carry trade we were unable to produce a better return than the S\&P 500 nor it produced a better Sharpe ratio contradicting Burnside et al. (2006), Lustig and Verdelhan (2007), Lusting et al. (2011), Menkhoff et al. (2012), Rafferty (2012) and Bhatti (2012) findings. Embedding a forecasting element in the selection process led to an improvement in all measuring criteria, except for the magnitude of error measures, confirming the findings of Della Corte et al. (2009), Jorda and Taylor (2009), Moosa (2010), Schmidbauer et al. (2010), Li (2011), Moosa and Halteh (2012). In terms of the relation between interest rate differential and mean return, we were unable to find such a relation in this exercise confirming the findings of Moosa (2008), Olmo and Pilbeam (2009) and Moosa and Halteh (2012). We were able to find a statistically significant relation between interest rate differential and exchange rate volatility confirming Galati et al. (2007), Hattori and Shin (2007), Brunnermeier et al. (2008), Tosborvorn (2010) and Jylha and Souminen (2011) findings. The paper also shows that conventional carry trade performs poorly during financial crises where exchange rate volatility is high, which is in line with Jorda and Taylor (2009) and Menkhoff et al. (2012) findings.

When it comes to over coming Meese-Rogoff (1983) random walk, our monetary model was unable to outperform it in terms of the magnitude of error measures. But, when looking at the outcome of the forecasting model from an economical point of view we can see that in terms of profitability the monetary model was able to outperform the random walk in that category. This finding answer the question of Leitch and Tanner (1991), Chow et al. (2007) and Moosa (2013) regarding the rationale behind buying forecasting models by profit-maximising firms since measures of forecasting accuracy indicate that the random walk produces better forecasts for free.

\section{Acknowledgements}

I would like to express my gratitude to Prof. Imad Moosa from RMIT University for his gaudiness and unconditional support. I would also like to thank the two anonymous referees for their thoughtful comments. 


\section{References}

Abhyankara, A., Sarnob, S., \& Valenteb, G. (2005). Exchange Rates and Fundamentals: Evidence on the Economic Value of Predictability. Journal of International Economics, 66, 325-348. http://dx.doi.org/10.1016/j.jinteco.2004.09.003

Adrian, T., Shin, H., \& Erkko, E. (2009). Risk Appetite and Exchange Rates. Federal Reserve Bank of New York Staff Reports, No. 361.

AlAli, M., \& AlKulaib, Y. (2015). Carry Trade Profitability Using Pegged Currency: A Case of the Qatari Riyal. International Journal of Economics and Finance, 7(10), 215-221. http://dx.doi.org/10.5539/ijef.v7n10p215

AlAli, M., AlAli, L., \& AlKhalifa, F. (2016). The Profitability of Using Pegged Currencies in Carry Trade: A Case of Saudi Riyal. Applied Economics and Finance, 3(1), 103-109. http://dx.doi.org/10.11114/aef.v3i1.1306

Baillie, R., \& Chang, S. (2011). Carry Trades, Momentum Trading and the Forward Premium Anomaly. Journal of Financial Markets, 14(3), 441-464. http://dx.doi.org/10.1016/j.finmar.2011.01.001

Bhatti, R. (2012). On Return and Risk in Carry Trades: A Case of the Pak Rupee. International Journal of Economic and Finance Studies, 4(2), 201-214.

Boothe, P., \& Glassman, D. (1987). Comparing Exchange Rate Forecasting Models: Accuracy versus Profitability, International Journal of Forecasting, 3, 65-79. http://dx.doi.org/10.1016/0169-2070(87)90079-3

Brunnermeier, M., Nagel, S., \& Pedersen, L. (2008). Carry Trades and Currency Crashes, National Bureau of Economic Research, November.

Burnside, C., M. Eichenbaum, I. Kleshchelski, \& S. Rebelo. (2006). The Returns to Currency Speculation. NBER Working Paper, no. 12489. Cambridge, MA: National Bureau of Economic Research.

Burnside, C., M. Eichenbaum, I. Kleshchelski, \& S. Rebelo. (2007). The Returns to Currency Speculation in Emerging Markets, NBER Working Paper, no. 12916. Cambridge, MA: National Bureau of Economic Research. http://dx.doi.org/10.1257/aer.97.2.333

Cheung, Y., M. Chinn, \& A. Garcia. (2005). Empirical Exchange Rate Models of the Nineties: Are Any Fit to Survive?. Journal of International Money and Finance, 24, 1150-1175. http://dx.doi.org/10.1016/j.jimonfin.2005.08.002

Chow, K., \& K. L. Y. Tan. (2007). The Use of Profits as Opposed to Conventional Forecast Evaluation Criteria to Determine the Quality of Economic Forecasts. Singapore: Nanyang Business School, Nanyang Technological University.

Clarida, R., Davis, J., \& Pedersen, N. (2009). Currency carry trade regimes: Beyond the Fama regression. Journal of International Money and Finance, 28(8), 1375-1389. http://dx.doi.org/10.1016/j.jimonfin.2009.08.010

Corte, P., Sarno, L., \& Tsiakas, I. (2009). An Economic Evaluation of Empirical Exchange Rate Models. Review of Financial Studies, 22, 3491-3530.

Darvas, Z. (2009). Leveraged Carry Trade Portfolios. Journal of Banking and Finance, 33(5), 944-957. http://dx.doi.org/10.1016/j.jbankfin.2008.10.007

Della Corte, P., L. Sarno, \& I. Tsiakas. (2009). An Economic Evaluation of Empirical Exchange Rate Models. Review of Financial Studies, 22, 3491-3530. http://dx.doi.org/10.1093/rfs/hhn058

Engel, C., \& Hamilton, J. (1990). Long Swings in the Dollar: Are They in the Data and Do Markets Know It?, American Economic Review, 80, 689-713.

Engel, C., Mark, N. C., \& West, K. D. (2007). Exchange rate models are not as bad as you think (No. w13318). National Bureau of Economic Research.

Engle, C. (1996). The Forward Discount Anomaly and the Risk Premium: A Survey of Recent Evidence. Journal of Empirical Finance, 3, 123-192. http://dx.doi.org/10.1016/0927-5398(95)00016-X

Eun, C., \& Sabherwal, S. (2002). Forecasting exchange rates: Do banks know better?. Global Finance Journal, 13(2), 195-215. http://dx.doi.org/10.1016/S1044-0283(02)00047-9

Fair, R. (2008). Estimating Exchange Rate Equations Using Estimated Expectations. Yale University ICF Working Paper, No. 07-18.

Flood, R., \& Rose, A. (2002). Uncovered Interest Parity in Crisis. IMF Staff Papers, No. 49. 
Frankel, J. A., \& Rose, A. K. (1995). A survey of empirical research on nominal exchange rates (No. C95-051). University of California at Berkeley.

Galati, G., Heath, A., \& McGuire, P. (2007). Evidence of Carry Trade Activity. BIS Quarterly Review, 27-41.

Greenaway-McGrevy, R., Mark, N., Sul, D., \& Wu, J. (2012). Exchange Rates as Exchange Rate Common Factors. Hong Kong Institute for Monetary Research Working Paper, No. 212012.

Gyntelberg, J., \& E. Remolona. (2007). Risk in Carry Trade: A Look at Target Currencies in Asia and the Pacific. BIS Quarterly Review, 4, 73-82.

Hattori, M., \& Shin, H. (2007). The Broad Yen Carry Trade. Institute for Monetary and Economic Studies Paper, No. 07-E-19, Bank of Japan.

Jorda, O., \& A. Taylor. (2009). The Carry Trade and Fundamentals: Nothing to Fear but FEER Itself. NBER Working Paper, no. 15518. Cambridge, MA: National Bureau of Economic Research. http://dx.doi.org/10.1016/j.jinteco.2012.03.001

Jylhä, P., \& M. Suominen. (2011). Speculative Capital and Currency Carry Trades. Journal of Financial Economics, 99(1), 60-75. http://dx.doi.org/10.1016/j.jfineco.2010.07.006

Kohler, D. (2008). Betting Against Uncovered Interest Rate Parity. Doctoral Thesis, University of St. Gallen, Dissertation No. 3513.

Leitch, G., \& J. Tanner. (1991). Economic Forecast Evaluation: Profit versus the Conventional Error Measures. American Economic Review, 81, 580-590.

Li, M. (2011). An Evaluation of Exchange Rate Models by Carry Trade. Journal of Economics and International Finance, 3, 72-87.

Liu, M., Margaritis, D., \& Tourani-Rad, A. (2012). Risk Appetite, Carry Trade and Exchange Rates. Global Finance Journal, 23, 48-63. http://dx.doi.org/10.1016/j.gfj.2012.01.004

Lustig, H., \& Verdelhan, A. (2007). The cross section of foreign currency risk premia and consumption growth risk. The American economic review, 97(1), 89-117.

Lustig, H., Roussanov, N., \& Verdelhan, A. (2011). Common risk factors in currency markets. Review of Financial Studies, 24(11), 3731-3777.

Maggiori, M. (2011). The U.S. Dollar Safety Premium. Working Paper, New York University.

Mark, N., \& Choi, D. (1997). Real Exchange Rate Prediction over Long Horizon. Journal of international Economics, 43, 29-60. http://dx.doi.org/10.1016/S0022-1996(96)01445-6

Meese, R., \& K. Rogoff. (1983). Empirical Exchange Rates Models of the Seventies: Do They Fit Out of Sample?. Journal of International Economics, 14, 3-24. http://dx.doi.org/10.1016/0022-1996(83)90017-X

Menkhoff, L., L. Sarno, M. Schmeling, \& A. Schrimpf. (2012). Carry Trades and Global Foreign Exchange Volatility. Journal of Finance, 67(2), 681-718. http://dx.doi.org/10.1111/j.1540-6261.2012.01728.x

Moosa, I. (2004). What Is Wrong with Market-Based Forecasting of Exchange Rates?. International Journal of Business and Economics, 3(2), 107-121.

Moosa, I. (2008). Risk and Return in Carry Trade. Journal of Financial Transformation, 22(3), 8-13.

Moosa, I. (2010). The Profitability of Carry Trade. Economia Internazionale, 63, 261-380.

Moosa, I. (2013). Why Is It so Difficult to Outperform the Random Walk in Exchange Rate Forecasting?. Journal of Applied Economics, 45, 3340-3346. http://dx.doi.org/10.1080/00036846.2012.709605

Moosa, I., \& Halteh, P. (2012). The Profitability of Carry Trade Relative to a Forecasting-Based Strategy. Journal of International Economics, 65(4), 605-621.

Moosa, I., \& K. Burns. (2012). Can Exchange Rate Models Outperform the Random Walk? Magnitude, Direction and Profitability as Criteria. Journal of International Economics (Economia Internazionale), 65(3), 473-490.

Neely, C., \& Weller, P. (2013). Lessons from the evolution of foreign exchange trading strategies. Journal of Banking and Finance, 37(10), 3783-3798. http://dx.doi.org/10.1016/j.jbankfin.2013.05.029

Olmo, J., \& Pilbeam, K. (2009). The Profitability of Carry Trades. Annals of Finance, 5, 231-241. http://dx.doi.org/10.1007/s10436-008-0098-2 
Plantin, G., \& Shin, H. (2006). Carry Trade and Speculative Dynamics, Princeton University Working Papers. http://dx.doi.org/10.2139/ssrn.898412

Rafferty, B. (2012). Currency returns, skewness and crash risk. Skewness and Crash Risk, March 15.

Ranaldo, A., \& Soderlind, P. (2010). Safe Haven Currencies. Review of Finance, 14, 385-407.

Schmidbauer, H., A. Rösch, T. Sezer, \& V. Tunalıglu. (2010). Currency Carry Trading with MGARCH Based Carry-to-Risk Portfolio Optimization. Proceedings of the 30th International Symposium on Forecasting ISF2010, San Diego, June 20-23.

Szilagyi, P., \& Batten, J. (2006). Arbitrage, Covered Interest Parity and Long-Term Dependence between the US Dollar and the Yan, IIIS Discussion Paper, No. 128.

The Economist. (2007). Economics focus: Carry on Speculating, February $22^{\text {nd }}$.

Thoma, M. (2008). FRB Dallas: Why Are Exchange Rates So Difficult to Predict?, Federal Reserve Bank of San Francisco Economic Letter, $22^{\text {nd }}$ July.

Tosborvorn, T. (2010). Exploring the Yen Carry Trade: Investor's Choice of Target Currencies, Stanford University. Retrieved from http://economics.stanford.edu/fi les/Tosborvorn_HThesis2010.pdf 